\title{
GLOBAL ASYMPTOTICS OF THE FILTRATION PROBLEM IN A POROUS MEDIUM
}

\author{
Lyudmila I. Kuzmina ${ }^{1}$, Yuri V. Osipov ${ }^{2}$, Yulia G. Zheglova ${ }^{2}$ \\ ${ }^{1}$ National Research University Higher School of Economics, Moscow, RUSSIA \\ ${ }^{2}$ National Research Moscow State University of Civil Engineering, Moscow, RUSSIA
}

\begin{abstract}
Filtration of the suspension in a porous medium is important when strengthening the soil and creating watertight partitions for the construction of tunnels and underground structures. A model of deep bed filtration with variable porosity and fractional flow, and a size-exclusion mechanism of particle retention are considered. A global asymptotic solution is constructed in the entire domain in which the filtering process takes place. The obtained asymptotics is close to the numerical solution.
\end{abstract}

Keywords: deep bed filtration, porous medium, suspended and retained particles, mathematical model, global asymptotics

\section{ГЛОБАЛЬНАЯ АСИМПТОТИКА ЗАДАЧИ ФИЛЬТРАЦИИ В ПОРИСТОЙ СРЕДЕ}

\author{
Л.И. Кузьмина ${ }^{1}$ Ю.В. Осипов ${ }^{2}$, Ю.Г. Жеглова ${ }^{2}$ \\ ${ }^{1}$ Национальный исследовательский университет «Высшая школа экономики», г. Москва, РОССИЯ \\ ${ }^{2}$ Национальный исследовательский Московский государственный строительный университет, \\ г. Москва, РОССИЯ
}

\begin{abstract}
Аннотация: Задачи фильтрации суспензии в пористой среде важны при укреплении грунта и создании водонепроницаемых перегородок для строительства туннелей и подземных сооружений. Рассматривается модель долговременной глубинной фильтрации с переменной пористостью и доступным потоком, и размерным механизмом задержания частиц. Строится глобальное асимптотическое решение во всей области, в которой происходит процесс фильтрации. Найденная асимптотика всюду близка к численному решению.
\end{abstract}

Ключевые слова: долговременная глубинная фильтрация, пористая среда, взвешенные и осажденные частицы, математическая модель, глобальная асимптотика

\section{INTRODUCTION}

Construction of tunnels and underground structures construction requires strengthening the soil and creation of watertight partitions protecting the structures from ground and flood waters. When pumping a liquefied solution of concrete into a porous soil, the grout penetrates into the pores and is filtered by porous rock. After drying and hardening of grout, the soil becomes durable and waterproof $[1,2]$.

When filtering the suspension in a porous medium, part of the solid particles is transferred from the inlet to the outlet of a porous sample, and some particles get stuck in the pores and form a deposit. Particles retention is influenced by different forces depending on the chemical and physical composition of the porous medium and suspension. There are many different filtration models with various mechanisms for the transport and deposition of particles [3-5]. If the size distribution of particles and pores overlap, then the main reason for particle retention becomes size-exclusion: solid suspended particles freely pass through large pores and get stuck at the inlet of small pores [6].

The classical mathematical model of deep bed filtration includes the mass balance equation for suspended and retained particles and the kinetic equation for deposit growth [7]. With a relative- 
ly small number of solid particles in suspension, deposit growth is proportional to the first degree of suspended particles concentration. In the general case the proportionality coefficient between the growth rate of the deposit and the suspended concentration depends nonlinearly on the retained particles concentration and is called the filtration coefficient. The exact solution of this problem was obtained in [8].

More complex filtration models suggest that the porosity and the fractional flow are not constant, but depend on retained particles concentration [9]. For a complicated system of equations, local asymptotic solutions were obtained near the porous medium inlet, on the concentrations front, and for large time [10-12]. However, it is not possible to construct a global asymptotics on the basis of these solutions, since the applicability domains of local asymptotics do not cover the entire zone in which the system of equations is considered.

In this paper, a new method for constructing a global asymptotic solution has been developed. On its basis, the global asymptotics of the deep bed filtration problem of a monodisperse suspension in a homogeneous porous medium is obtained. Coordinate transformation leads to a variable that is small in the entire filtration zone. The global asymptotic solution is constructed as a series in powers of the new variable. The asymptotics is compared with the numerical solution obtained by the finite difference method [13-15]. The calculations show that the asymptotic and numerical solutions are close in the entire filtration zone.

\section{MATHEMATICAL MODEL}

A one-dimensional model of deep bed filtration of suspensions and colloids in a porous medium with variable porosity and fractional flow in the domain $\Omega=\{0 \leq x \leq 1, t \geq 0\}$ is determined by a quasilinear hyperbolic system of two first-order equations

$$
\begin{gathered}
\frac{\partial}{\partial t}(\mathrm{~g}(S) C)+\frac{\partial}{\partial x}(f(S) C)+\frac{\partial S}{\partial t}=0 \\
\frac{\partial S}{\partial t}=\Lambda(S) C
\end{gathered}
$$

Here $g(S), f(S)$ are smooth positive functions for $S \geq 0$; the blocking filtration coefficient $\Lambda(S)$ is positive for $0 \leq S<S_{\max }$ and turns to zero for $S=S_{\max }$; unknown functions $C(x, t) ; S(x, t)$ are concentrations of suspended and retained particles.

The unique solution to the system (1), (2) is determined by the initial and boundary conditions

$$
\begin{gathered}
\left.C\right|_{x=0}=1 ; \\
\left.C\right|_{t=0}=0 ;\left.\quad S\right|_{t=0}=0 .
\end{gathered}
$$

Condition (3) means that a suspension of constant concentration is injected at the inlet of the porous medium; condition (4) corresponds to the absence of suspended and retained particles in the porous medium at the initial moment.

The concentrations front of suspended and retained particles moves in a porous medium from the inlet to the outlet at a constant velocity $v=f(0) / g(0)$ and is determined by formula $t=\alpha x, \alpha=g(0) / f(0)$.

Before the front in the domain $\Omega_{0}=\{0 \leq x \leq 1,0 \leq t \leq \alpha x\}$, the porous medium is empty, and the problem has a zero solution. Behind the concentration front in the domain $\Omega_{S}=\{0 \leq x \leq 1, t \geq \alpha x\}$, the porous medium contains suspended and retained particles, and the solution is positive. Since conditions (3) and (4) are not consistent at the origin, the solution $C(x, t)$ is discontinuous on the concentration front; the solution $S(x, t)$ is continuous in the domain $\Omega$ and vanishes on the front

$$
\left.S\right|_{t=\alpha x}=0
$$


In the domain $\Omega_{S}$, the solution of the original problem (1) - (4) coincides with the solution of problem (1) - (3), (5).

For constant coefficients $g=g_{0}, f=f_{0}$ of equation (1) and linear blocking filtration coefficient (Langmuir coefficient)

$$
\Lambda(S)=a-b S ; \quad a>0, b>0
$$

the simplified problem (1) - (3), (5) in the domain $\Omega_{s}$ has an exact solution

$$
\begin{aligned}
& C(x, t)=\frac{e^{b(t-\alpha x)}}{e^{b(t-\alpha x)}+e^{a x / f_{0}}-1} ; \\
& S(x, t)=\frac{a}{b} \cdot \frac{e^{b(t-\alpha x)}-1}{e^{b(t-\alpha x)}+e^{a x / f_{0}}-1} .
\end{aligned}
$$

In the general case, the exact solution of problem (1) - (3), (5) cannot be written down by explicit formulas [16]; therefore, asymptotics are constructed.

In characteristic variables $\tau=t-\alpha x, y=x$, the concentration front is given by the equation $\tau=0$. In the half-strip $\Omega^{\prime}=\{0 \leq y \leq 1, \tau \geq 0\}$, problem (1) - (3), (5). takes the form

$$
\begin{gathered}
\frac{\partial((\mathrm{g}(S)-\alpha f(S)) C)}{\partial \tau}+\frac{\partial(f(S) C)}{\partial y}+\frac{\partial S}{\partial \tau}=0 ; \\
\frac{\partial S}{\partial \tau}=\Lambda(S) C ; \\
\left.C\right|_{y=0}=1 ;\left.\quad S\right|_{\tau=0}=0 .
\end{gathered}
$$

Near the concentration front, the local asymptotic solution of the problem (8) - (10) is constructed using the small parameter $\tau$.

\section{ASYMPTOTIC SOLUTION}

A change of variables in the system (8) - (10)

$$
z=1-e^{-a y / f_{0}} ; T=1-e^{-b \tau}
$$

allows to use $z$ as a small parameter, because for $(y, \tau) \in \Omega^{\prime}$ the variables $z, T$ belong to the domain $\Omega^{\prime \prime}=\left\{0 \leq z \leq 1-e^{a / f_{0}}<1,0 \leq T<1\right\}$.

In the new variables, the solution (7) of the simplified problem takes the form

$$
C(\mathrm{z}, \tau)=\frac{1-z}{1-z T} ; \quad S(\mathrm{z}, \tau)=\frac{a}{b} \cdot \frac{(1-z) T}{1-z T} .
$$

Assume that the coefficients of equation (8) are almost constant, and the filtration coefficient differs little from a linear function:

$$
\begin{gathered}
g(S)=g_{0}+\varepsilon S G(S) ; \\
f(S)=f_{0}+\varepsilon S F(S) ; \\
\Lambda(S)=a-b S+\varepsilon S^{2} \lambda(S)
\end{gathered}
$$

Here $\varepsilon>0$ is a small parameter.

In the domain $\Omega^{\prime \prime}$ the problem (8)-(10) takes the form

$$
\begin{gathered}
b(1-T) \varepsilon S(G(S)-\alpha F(S)) \frac{\partial C}{\partial T}+a(1-z)\left(1+\varepsilon \frac{S F(S)}{f_{0}}\right) \frac{\partial C}{\partial z}+ \\
+\left(\varepsilon(\operatorname{SG}(S)-\alpha S F(S))^{\prime} \Lambda(S) C+\varepsilon(S F(S))^{\prime} \frac{a}{f_{0}}(1-z) \frac{\partial S}{\partial z}+\Lambda(S)\right) C=0 \\
b(1-T) \frac{\partial S}{\partial T}=\left(a-b S+\varepsilon S^{2} \lambda(S)\right) C \\
\left.C\right|_{z=0}=1 ;\left.\quad S\right|_{T=0}=0
\end{gathered}
$$

A solution of equations (8)-(10) is obtained in the form of a double series in powers of $\varepsilon, z$ : 


$$
\begin{aligned}
& C(\varepsilon, z, T)=1+\sum_{i=0}^{n} \sum_{j=1}^{m} c_{i, j}(T) \varepsilon^{i} z^{j} / j !=1+z\left(c_{0,1}+\varepsilon c_{1,1}+\varepsilon^{2} c_{2,1}+\ldots\right)+ \\
& +\frac{z^{2}}{2}\left(c_{0,2}+\varepsilon c_{1,2}+\varepsilon^{2} c_{2,2}+\ldots\right)+\ldots ; \\
& \quad S(\varepsilon, z, T)=\sum_{i=0}^{n} \sum_{j=0}^{m} s_{i, j}(T) \varepsilon^{i} z^{j} / j !=\left(s_{0,0}+\varepsilon s_{1,0}+\varepsilon^{2} s_{2,0}+\ldots\right)+ \\
& \quad+z\left(s_{0,1}+\varepsilon s_{1,1}+\varepsilon^{2} s_{2,1}+\ldots\right)+\frac{z^{2}}{2}\left(s_{0,2}+\varepsilon s_{1,2}+\varepsilon^{2} s_{2,2}+\ldots\right)+\ldots
\end{aligned}
$$

The coefficients $c_{i, j}, s_{i, j}$ depend only on $T$.

From conditions (16): $c_{i, 0}=0 ;\left.s_{i j}\right|_{T=0}=0$.

$\varepsilon^{0} z^{0}: b(1-T) s_{0,0}^{\prime}=\left(a-b s_{0,0}\right) \cdot 1$;

$\varepsilon^{0} z^{0}: a c_{0,1}+\left(a-b s_{0,0}\right) \cdot 1=0$;

$\varepsilon^{0} z^{1}: b(1-T) s_{0,1}^{\prime}=-b s_{0,1} \cdot 1+\left(a-b s_{0,0}\right) c_{0,1} ;$

$\varepsilon^{0} z^{1}: a c_{0,2}-a c_{0,1}-b s_{0,1} \cdot 1+\left(a-b s_{0,0}\right) c_{0,1}=0$;

$\varepsilon^{1} z^{0}: b(1-T) s_{1,0}^{\prime}=\left(-b s_{1,0}+s_{0,0}^{2} \lambda\left(s_{0,0}\right)\right) \cdot 1+\left(a-b s_{0,0}\right) \cdot 0$;

$\varepsilon^{1} z^{0}: a c_{1,1}+a \frac{s_{0,0} F\left(s_{0,0}\right)}{f_{0}} c_{0,1}+\left.(S G(S)-\alpha S F(S))^{\prime}\right|_{S=s_{0,0}} \cdot\left(a-b s_{0,0}\right) \cdot 1+$

$+\left.(S F(S))^{\prime}\right|_{S=s_{0,0}} \frac{a}{f_{0}} s_{0,1}+\left(-b s_{1,0}+s_{0,0}^{2} \lambda\left(s_{0,0}\right)\right) \cdot 1+\left(a-b s_{0,0}\right) \cdot 0=0$

$\varepsilon^{1} z^{1}: b(1-T) s_{1,1}^{\prime}=-b s_{1,1}+\left.\left(S^{2} \lambda(S)\right)^{\prime}\right|_{S=s_{0,0}} \cdot s_{0,1}-b s_{1,0} c_{0,1}+\left(a-b s_{0,0}\right) c_{1,1}+s_{0,0}^{2} \lambda\left(s_{0,0}\right) c_{0,1} \cdot$

Solving equations sequentially, the coefficients of expansions (17), (18) are obtained

$$
\begin{aligned}
& s_{0,0}=\frac{a}{b} T ; \quad c_{0,1}=T-1 ; \quad s_{0,1}=\frac{a}{b} T(T-1) ; \\
& c_{0,2}=2 T(T-1) ; \quad \ldots .
\end{aligned}
$$

Since the parameters $\varepsilon, z$ are small in the entire domain $\Omega^{\prime \prime}$, the expansions (17), (18) determine the global asymptotic solution of problem (14) (16) in the domain $\Omega^{\prime \prime}$.

\section{NUMERICAL CALCULATION}

The calculations were performed for the homogeneous porous medium [10]
Substituting the expansions (17), (18) into equations (14), (15) and equating the terms with the same degrees of $\varepsilon, z$, implies a recurrent system of differential and algebraic equations coefficients calculated in the laboratory of the University of Adelaide (Australia) in the study of deep bed filtration of a monodisperse suspension with particles of radius $r=2.179 \mu \mathrm{m}$ in a

$$
\begin{gathered}
g(S)=0.9743-8.88 \cdot 10^{-14} S+1.27 \cdot 10^{-11} S^{2}-1.24 \cdot 10^{-9} S^{3} \\
f(S)=0.9947+6.27 \cdot 10^{-5} S-2.9 \cdot 10^{-8} S^{2}+6.21 \cdot 10^{-10} S^{3} \\
\Lambda(S)=0.51-5.956 \cdot 10^{-3} S+2.29 \cdot 10^{-6} S^{2}+1.35 \cdot 10^{-8} S^{3}
\end{gathered}
$$


In expansions (17), (18) of the nonlinear problem (14) - (16), terms were calculated up to $\varepsilon^{1}$ and $z^{5}$. The asymptotics was compared with a numerical calculation performed by the finite difference method. The equations (1), (2) was approximated by an original second-order scheme using the trapezium method [17]. The obtained solution was compared with the exact solution (7) of the simplified problem with a linear filtration coefficient.

Figures 1-5 show graphs of global asymptotics (red line), numerical solution (blue line), and exact solution (7) (green line). Full graph images are in the center of Fig. 1-4; their enlarged fragments are shown on the left and right.
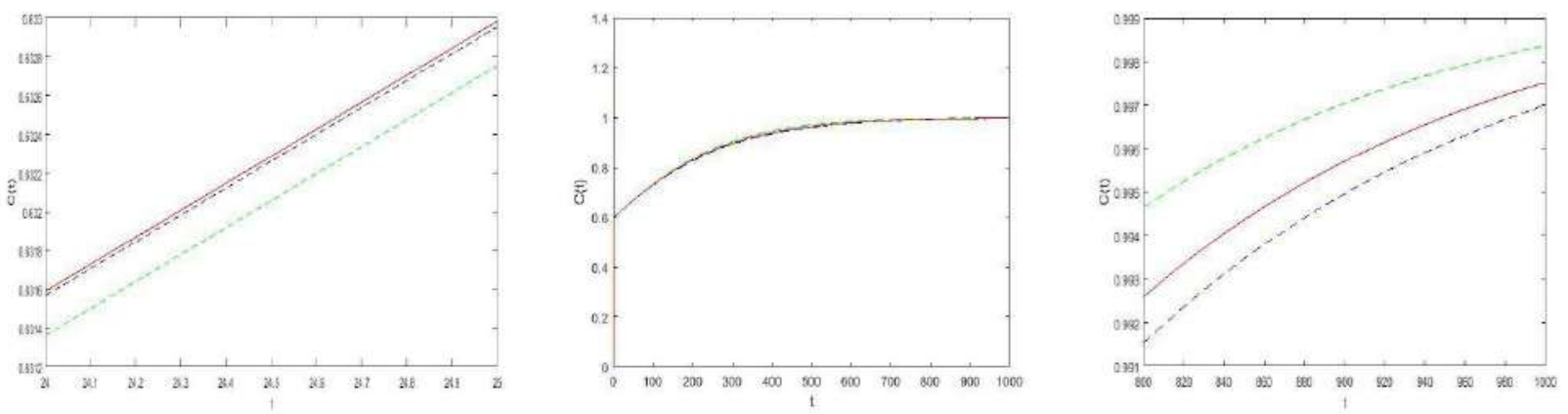

Figure 1. Graphs of suspended particles concentration $C(1, t)$ at the porous medium outlet.
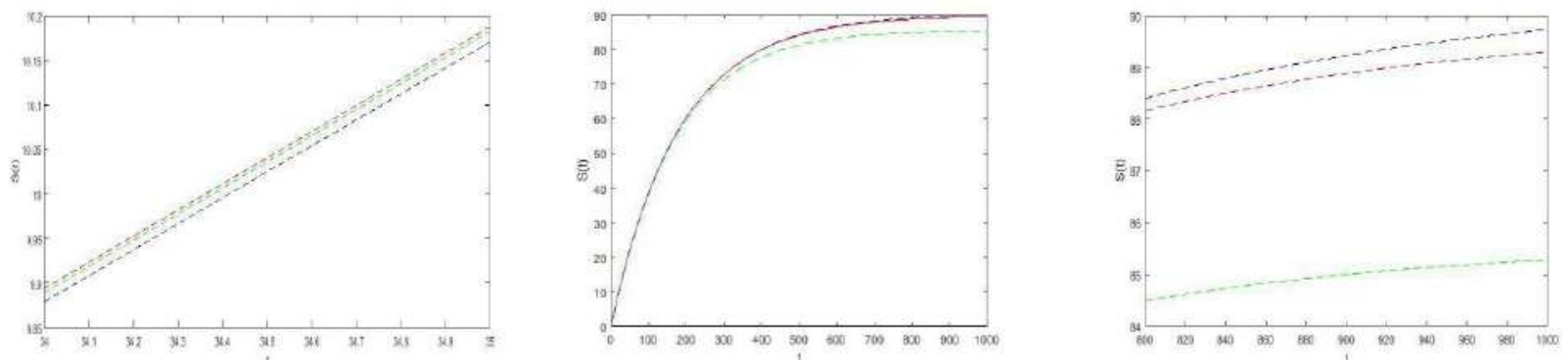

Figure 2. Graphs of retained particles concentration $S(1, t)$ at the porous medium outlet.
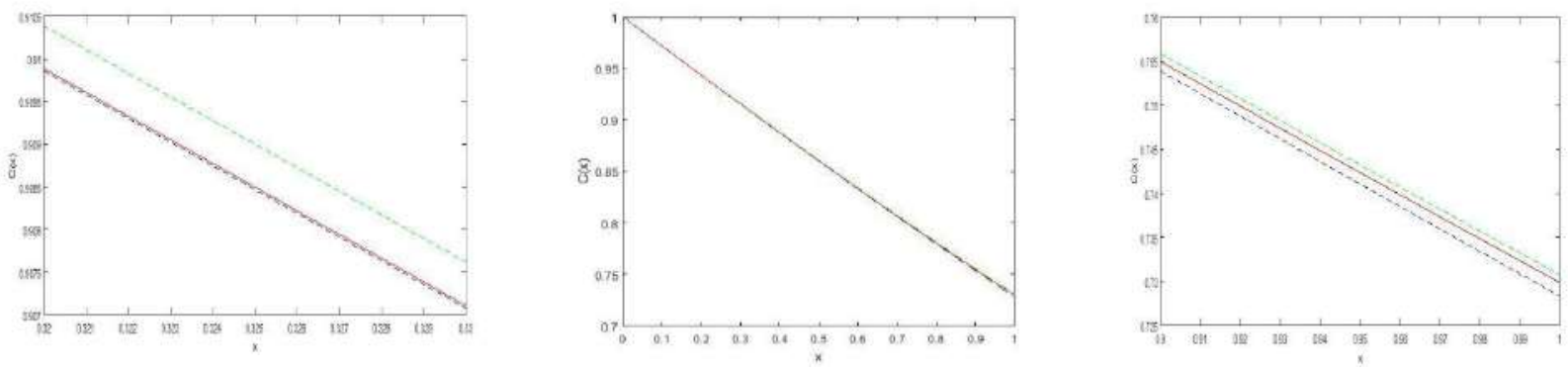

Figure 3. Graphs of suspended particles concentration $C(x, 100)$

at the fixed moment $t=100$.
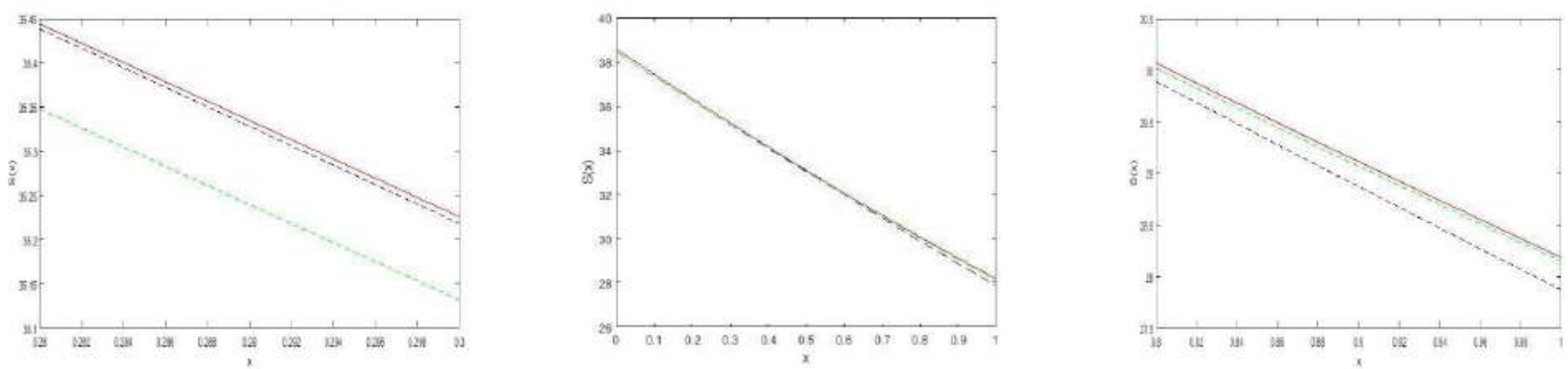

Figure 4. Graphs of retained particles concentration $S(x, 100)$

at the fixed moment $t=100$. 


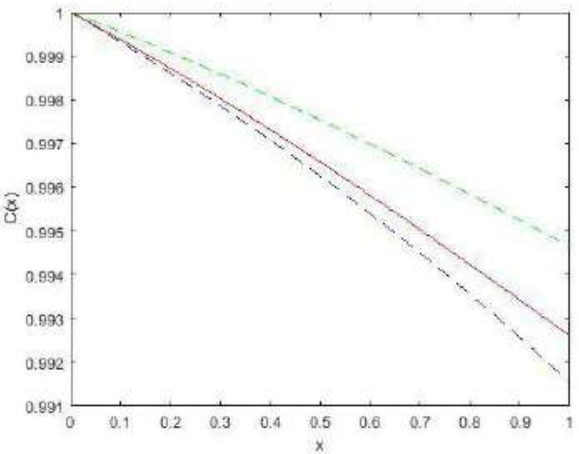

a) $C(x, 800)$

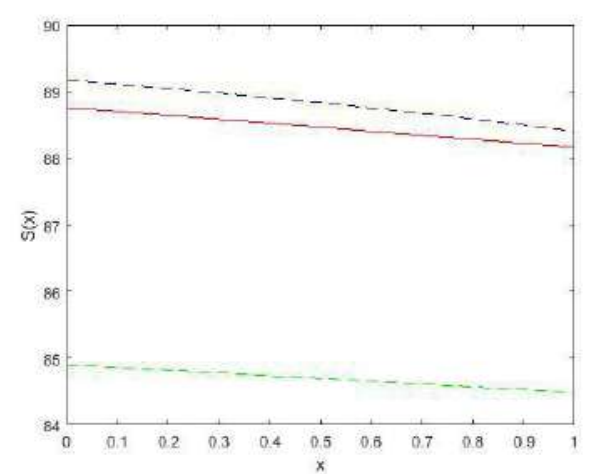

b) $S(x, 800)$

Figure 5. Graphs of suspended and retained particles concentration at the fixed moment $t=800$.

Graphs of global asymptotics and numerical solutions are close to each other, the discrepancy increases with increasing coordinate $x$. The greatest deviation is observed at the outlet $x=1$ at time $t=200: 1,6 \%$ for $C$ and $1,1 \%$ for $S$. The graphs of the exact solution (7) for the linear case are further away from the numerical solution than the asymptotic graphs.

\section{CONCLUSION}

A mathematical model of deep bed filtration with variable porosity and fractional flow does not have an exact solution in explicit form. Asymptotic and numerical methods are used to obtain the solution.

The global asymptotics approximates well the solution in the entire domain in which the suspension or colloid is filtered. Deviation increases with time.

The exact solution (7) of the simplified problem is not suitable for approximating the solution of a complex system.

The global asymptotics extends the possibilities of solving the inverse filtration problem - determining the coefficients (19) of system (1) (4) from a known suspended particles concentration at the porous medium outlet

[18-20].

The obtained asymptotic solutions can be used to fine-tune laboratory experiments [21], which significantly reduces the amount and cost of research.

\section{REFERENCES}

1. Tsuji M., Kobayashi S., Mikake S., Sato T., Matsui H. Post-Grouting Experiences for Reducing Groundwater Inflow at $500 \mathrm{~m}$ Depth of the Mizunami Underground Research Laboratory, Japan. // Procedia Engineering, 2017, vol. 191, pp. 543-550.

2. Lyapidevskaya $\mathbf{O}$. Grouting mortar for annular injection. // MATEC Web of Conferences, 2018, vol. 251, 01004.

3. Bedrikovetsky P. Mathematical theory of oil and gas recovery: with applications to ex-USSR oil and gas fields. Springer Science \& Business Media, 2013.

4. Civan F. Reservoir formation damage, third ed. Gulf Professional Publishing, Burlington, MA, USA, 2014.

5. Tien C., Ramarao B.V. Granular filtration of aerosols and hydrosols. Amsterdam, Elsevier, 2007.

6. Badalyan A., You Z., Aji K., Bedrikovetsky P., Carageorgos T., Zeinijahromi A. Size exclusion deep bed filtration: Experimental and modelling uncertainties. // Review of Scientific Instruments, 2014, vol. 85(1), 015111.

7. Herzig J.P., Leclerc D.M., Legoff P. Flow of suspensions through porous media application to deep filtration. // Industrial and Engineering Chemistry, 1970, vol. 62(5), pp. 8-35.

8. Vyazmina E.A., Bedrikovetskii P.G., Polyanin A.D. New classes of exact 
solutions to nonlinear sets of equations in the theory of filtration and convective mass transfer. // Theoretical Foundations of Chemical Engineering, 2007, vol. 41(5), pp. 556-564.

9. Bedrikovetsky P. Upscaling of stochastic micro model for suspension transport in porous media. // Transport in Porous Media, 2008, vol. 75, pp. 335-369.

10. You Z., Osipov Y., Bedrikovetsky P., Kuzmina L. Asymptotic model for deep bed filtration. // Chemical Engineering Journal, 2014, vol. 258, pp. 374-385.

11. Kuzmina L.I., Osipov Yu.V. Particle transportation at the filter inlet. // International Journal for Computational Civil and Structural Engineering, 2014, Volume 10, Issue 3, pp. 17-22.

12. Kuzmina L.I., Osipov Yu.V. Asymptotic model of filtration in almost stationary mode. // International Journal for Computational Civil and Structural Engineering, 2016, Volume 12, Issue 1, pp. 158-163.

13. Toro E.F. Riemann solvers and numerical methods for fluid dynamics. Dordrecht, Springer, 2009.

14. Galaguz Y.P. Realization of the TVDscheme for a numerical solution of the filtration problem. // International Journal for Computational Civil and Structural Engineering, 2017, Volume 13, Issue 2, pp. 93102.

15. Galaguz Y.P., Safina G.L. Modeling of fine migration in a porous medium. // MATEC Web of Conferences, 2016, vol. 86, 03003.

16. Bedrikovetsky P., You Z., Badalyan A., Osipov Y., Kuzmina L. Analytical model for straining-dominant large-retention depth filtration. // Chemical Engineering Journal, 2017, vol. 330, pp. 1148-1159.

17. Osipov Yu., Safina G., Galaguz Yu. Calculation of the filtration problem by finite differences methods. // MATEC Web of Conferences, 2018, vol. 251, 04021.

18. Alvarez A.C., Bedrikovetsky P.G., Hime G., Marchesin A.O., Marchesin D., Ro- drigues J.R. A fast inverse solver for the filtration function for flow of water with particles in porous media. // Inverse Problems, 2006, vol. 22, pp. 69-88.

19. Alvarez A.C., Hime G., Marchesin D., Bedrikovetsky P.G. The inverse problem of determining the filtration function and permeability reduction in flow of water with particles in porous media. // Transport in Porous Media, 2007, vol. 70(1), pp. 4362.

20. Alvarez A.C., Hime G., Silva J.D., Marchesin D. Analytic regularization of an inverse filtration problem in porous media. // Inverse Problems, 2013, vol. 29, 025006.

21. Vaz A., Bedrikovetsky P., Fernandes P.D., Badalyan A., Carageorgos T. Determining model parameters for non-linear deep-bed filtration using laboratory pressure measurements. // Journal of Petroleum Science and Engineering, 2017, vol. 151, pp. 421-433.

\section{СПИСОК ЛИТЕРАТУРЫ}

1. Tsuji M., Kobayashi S., Mikake S., Sato T., Matsui H. Post-Grouting Experiences for Reducing Groundwater Inflow at $500 \mathrm{~m}$ Depth of the Mizunami Underground Research Laboratory, Japan. // Procedia Engineering, 2017, vol. 191, pp. 543-550.

2. Lyapidevskaya O. Grouting mortar for annular injection. // MATEC Web of Conferences, 2018, vol. 251, 01004.

3. Bedrikovetsky P. Mathematical theory of oil and gas recovery: with applications to ex-USSR oil and gas fields. Springer Science \& Business Media, 2013.

4. Civan F. Reservoir formation damage, third ed. Gulf Professional Publishing, Burlington, MA, USA, 2014.

5. Tien C., Ramarao B.V. Granular filtration of aerosols and hydrosols. Amsterdam, Elsevier, 2007.

6. Badalyan A., You Z., Aji K., Bedrikovetsky P., Carageorgos T., Zeinijahromi 
A. Size exclusion deep bed filtration: Experimental and modelling uncertainties. // Review of Scientific Instruments, 2014, vol. 85(1), 015111.

7. Herzig J.P., Leclerc D.M., Legoff P. Flow of suspensions through porous media application to deep filtration. // Industrial and Engineering Chemistry, 1970, vol. 62(5), pp. 8-35.

8. Vyazmina E.A., Bedrikovetskii P.G., Polyanin A.D. New classes of exact solutions to nonlinear sets of equations in the theory of filtration and convective mass transfer. // Theoretical Foundations of Chemical Engineering, 2007, vol. 41(5), pp. 556-564.

9. Bedrikovetsky P. Upscaling of stochastic micro model for suspension transport in porous media. // Transport in Porous Media, 2008, vol. 75, pp. 335-369.

10. You Z., Osipov Y., Bedrikovetsky P., Kuzmina L. Asymptotic model for deep bed filtration. // Chemical Engineering Journal, 2014, vol. 258, pp. 374-385.

11. Kuzmina L.I., Osipov Yu.V. Particle transportation at the filter inlet. // International Journal for Computational Civil and Structural Engineering, 2014, Volume 10, Issue 3, pp. 17-22.

12. Kuzmina L.I., Osipov Yu.V. Asymptotic model of filtration in almost stationary mode. // International Journal for Computational Civil and Structural Engineering, 2016, Volume 12, Issue 1, pp. 158-163.

13. Toro E.F. Riemann solvers and numerical methods for fluid dynamics. Dordrecht, Springer, 2009.

14. Galaguz Y.P. Realization of the TVDscheme for a numerical solution of the filtration problem. // International Journal for Computational Civil and Structural Engineering, 2017, Volume 13, Issue 2, pp. 93102.

15. Galaguz Y.P., Safina G.L. Modeling of fine migration in a porous medium. // MATEC Web of Conferences, 2016, vol. 86, 03003.
16. Bedrikovetsky P., You Z., Badalyan A., Osipov Y., Kuzmina L. Analytical model for straining-dominant large-retention depth filtration. // Chemical Engineering Journal, 2017, vol. 330, pp. 1148-1159.

17. Osipov Yu., Safina G., Galaguz Yu. Calculation of the filtration problem by finite differences methods. // MATEC Web of Conferences, 2018, vol. 251, 04021.

18. Alvarez A.C., Bedrikovetsky P.G., Hime G., Marchesin A.O., Marchesin D., Rodrigues J.R. A fast inverse solver for the filtration function for flow of water with particles in porous media. // Inverse Problems, 2006, vol. 22, pp. 69-88.

19. Alvarez A.C., Hime G., Marchesin D., Bedrikovetsky P.G. The inverse problem of determining the filtration function and permeability reduction in flow of water with particles in porous media. // Transport in Porous Media, 2007, vol. 70(1), pp. 4362.

20. Alvarez A.C., Hime G., Silva J.D., Marchesin D. Analytic regularization of an inverse filtration problem in porous media. // Inverse Problems, 2013, vol. 29, 025006.

21. Vaz A., Bedrikovetsky P., Fernandes P.D., Badalyan A., Carageorgos T. Determining model parameters for non-linear deep-bed filtration using laboratory pressure measurements. // Journal of Petroleum Science and Engineering, 2017, vol. 151, pp. 421-433.

Lyudmila I. Kuzmina, Candidate of Physical and Mathematical Sciences, Associate Professor, Department of Applied Mathematics, National Research University Higher School of Economics; 20, Myasnitskaya st., Moscow, 101000, Russia; phone +7(495) 772959015219 ;

E-mail: lkuzmina@hse.ru.

Yuri V. Osipov, Candidate of Physical and Mathematical Sciences, Associate Professor, Department of Applied Mathematics, National Research Moscow State University of Civil Engineering; 26, Yaroslavskoe Shosse, Moscow, 129337, Russia; phone +7(499)1835994;

E-mail: yuri-osipov@mail.ru. 
Global Asymptotics of the Filtration Problem in a Porous Medium

Yulia G. Zheglova, Assistant Professor, Department of Applied Mathematics, National Research Moscow State University of Civil Engineering; 26, Yaroslavskoe Shosse, Moscow, 129337, Russia;

phone +7(499)1835994;

E-mail: uliagermanovna@yandex.ru.

Кузьмина Людмила Ивановна, доцент, кандидат физико-математических наук, Департамент прикладной математики, Национальный исследовательский университет «Высшая школа экономики»; 101000, г. Москва, ул. Мясницкая, д. 20, тел. +7(495) 7729590 *15219; e-mail: lkuzmina@hse.ru.

Осипов Юрий Викторович, доцент, кандидат физикоматематических наук; кафедра прикладной математики, Национальный исследовательский Московский государственный строительный университет; 129337, Россия, г. Москва, Ярославское шоссе, д. 26; тел. +7(499)1835994; e-mail: yuri-osipov@ mail.ru.

Жеглова Юлия Германовна, преподаватель; кафедра прикладной математики, Национальный исследовательский Московский государственный строительный университет; 129337, Россия, г. Москва, Ярославское шоссе, д. 26; тел. +7(499)1835994;

E-mail: uliagermanovna@yandex.ru. 